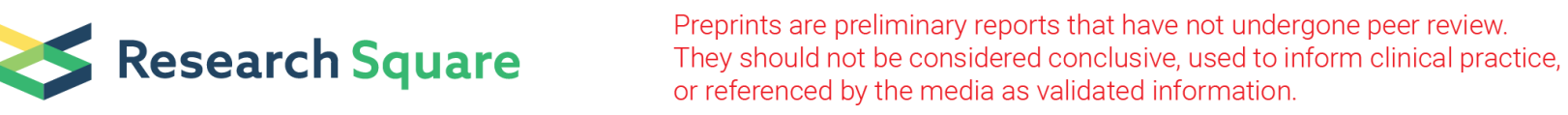

\title{
Exploration of the Mutual Effects Between Cation- $\pi$ and Intramolecular Hydrogen Bond Interactions in the Different Complexes of Mesalazine with Metal Cations of Alkali and Alkaline-Earth: A DFT Study
}

Marziyeh Mohammadi ( $\square$ mohammadrezapoorheravi@yahoo.com )

Rafsanjan University of Vali Asr

Fahimeh Alirezapour

Payame Noor University Department of Chemistry

Azadeh Khanmohammadi

Payame Noor University Department of Chemistry

Research Article

Keywords: Cation $\llbracket \pi$, Intramolecular hydrogen bond, DFT, AIM, NBO

Posted Date: June 2nd, 2021

DOI: https://doi.org/10.21203/rs.3.rs-531422/v1

License: (9) (1) This work is licensed under a Creative Commons Attribution 4.0 International License. Read Full License 


\section{Abstract}

In the current research, a comparative study of the interplay effects between cation- $\pi$ and intramolecular hydrogen bond (IMHB) interactions is performed on the complexes of mesalazine with $\mathrm{Li}^{+}, \mathrm{Na}^{+}, \mathrm{K}^{+}, \mathrm{Be}^{2+}, \mathrm{Mg}^{2+}$ and $\mathrm{Ca}^{2+}$ cations using density functional theory (DFT). For this purpose, the mesalazine analogue and the equivalent values of 3 -aminobenzoic acid complexes with the cited cations are selected as a set of reference points. In order to understand the mutual effects between these interactions, the descriptors of geometrical, binding energies, topological properties and charge transfer values are examined on complexes using the atoms in molecules (AIM) and natural bond orbital (NBO) analyses. Results indicate that with the exception of $\mathrm{Be}^{2+}$ complex, the coupling simultaneously weakens both of the interactions. Finally, the physical properties such as energy gap, chemical hardness as well as electronic chemical potential of complexes are systematically analyzed by using frontier molecular orbitals.

\section{Introduction}

Mesalazine (MES), also known as mesalamine or 5-aminosalicylic acid, is a medication used to treat inflammatory bowel disease, including ulcerative colitis and Crohn's disease [1]. It is a bowel specific aminosalicylate drug that after oral administration is metabolized in the gut and has its predominant actions there [2]. Consequently there are fewer side effects. The MES is structurally related to the salicylates. It differs both structurally and therapeutically from 4-aminosalicylic acid (or p-aminosalicylic acid). The mechanism by which MES acts during the treatment of inflammatory bowel disease remains unknown, but this drug is believed to work through modulation of the chemical mediators of inflammatory response, particularly prostaglandins and leukotrienes. The MES inhibits the cyclooxygenase enzyme in the arachidonic acid cascade, thereby reducing the production of inflammatory prostaglandins [3-5].

Noncovalent interactions (NCls) such as hydrogen bond (HB), cation $-\pi$, anion $-\pi, \pi-\pi$, etc. play an important role in many areas of science and technology, as well as materials and catalysis. These interactions are essential in chemical reactions and regulation of biochemical processes [6]. The HB has been extremely well studied and recognized as the most important indicator of $\mathrm{NCl}[7,8]$. The $\mathrm{HB}$ plays vital roles in biological structure, function, and conformational dynamics and is fundamental to life as it has evolved on Earth [9]. The characteristics of $\mathrm{HBs}(\mathrm{X}-\mathrm{H} \bullet . . \mathrm{Y})$ are not only dependent on the properties of $\mathrm{X}, \mathrm{Y}$, and $\mathrm{H}$ but also are related to other factors such as substituent, hybridization, and solvation [10-12]. Cation- $\pi$ interactions, as another ensemble of NCls, describe the association between a cation and the face of a molecule containing a $\pi$-system [13-15]. The importance of NCls involving aromatic systems becomes major in drug receptor interactions, crystal engineering and protein folding [16]. The strength of cation- $\pi$ interaction is usually greater than other $\mathrm{NCls}$ associated with the $\pi-s y s t e m$, such as $\pi-\pi$ and $\pi-\mathrm{HB}[13]$ and its importance is depends on the character of both the $\pi$-system and the cation involved in the interaction [17-19].

The understanding of the interplay among NCls is important for the improvement of fields such as supramolecular chemistry and molecular recognition [20]. Several theoretical calculations have been reported on the interplay between cation $-\pi$ and HB interactions in the different systems. Frontera et al. [21] studied the interplay among three important $\mathrm{NCls}(\mathrm{HB}$, cation $-\pi$ and $\pi-\pi)$ involving aromatic rings by means of ab initio calculations. They demonstrated that synergetic effects are present in complexes where these interactions coexist. In 2017, Nowroozi et al. [22] investigated interplay between the IMHB and cation- $\pi$ interactions in the 
various complexes of salicylaldehyde, thiosalicylaldehyde and selenosalicylaldehyde with $\mathrm{Li}^{+}, \mathrm{Na}^{+}, \mathrm{K}^{+}, \mathrm{Mg}^{2+}$ and $\mathrm{Ca}^{2+}$ cations. Also, a comparative study of the cooperative effects between the cation- $\pi$ and IMHB interactions in the various complexes of ortho-aminobenzaldehyde with its thio and seleno analogous analyzed in 2017 [23].

The main objective of this study is to explore the interplay effects between cation $-\pi$ and IMHB interactions in the complexes of mesalazine with $\mathrm{Li}^{+}, \mathrm{Na}^{+}, \mathrm{K}^{+}, \mathrm{Be}^{2+}, \mathrm{Mg}^{2+}$ and $\mathrm{Ca}^{2+}$ cations. Hence, the different descriptors such as energetic, geometrical, spectroscopic and topological parameters are analyzed and their results are compared to the parent molecule of mesalazine and the 3-aminobenzoic acid (ABA) complexes with the cited cations as a set of suggestion points. For this work, the AIM and NBO analyses are performed by DFT calculations. The study is extended to the molecular orbital analysis to calculate the energy gap, global hardness and electronic chemical potential of the considered complexes. Due to the biological significance of these ions, it is important to study complexation with bioactive ligands to identify functions of their complexes and to discover new bioactive compounds.

\section{Computational Methods}

Theoretical calculations are performed using Gaussian 09 program package [24]. Density functional theory [25] has been shown to be a powerful and useful tool for the study of noncovalent complexes. In this work, the geometries are optimized by wB97XD method using 6-311 ++ G(d,p) basis set [26]. This method involves the long-range correction with empirical atom-atom dispersion [27-30]. Frequency calculations are performed for complexes at the same level of theory. The absence of imaginary frequencies verifies that all structures are true minima. The binding energies $(\triangle \mathrm{E})$ are computed as the difference between the energy of the complex $(\mathrm{AB})$ and the combination of the energies of the isolated species $A$ and $B$ as follows [31, 32]:

$\Delta \mathrm{E}=\mathrm{E}_{\mathrm{AB}}-\left(\mathrm{E}_{\mathrm{A}}+\mathrm{E}_{\mathrm{B}}\right)$

The binding energies are corrected for the basis set superposition error by the Boys-Bernardi counterpoise technique [33]. The QTAIM [34] analysis is performed with the help of AIM2000 program [35] on the wave functions obtained at the wB97XD/6-311 ++G(d,p) level of theory. The NBO analysis [36, 37] gives an idea of the participation of each atomic orbital in the molecular bonds. This calculation is carried out using the version 3.1 of the NBO package [38] included in the Gaussian 09 program. Finally, the energies of the highest occupied molecular orbital (HOMO) and the lowest unoccupied molecular orbital (LUMO) are computed to evaluate the physical properties of the studied complexes.

\section{Results And Discussion}

In order to study the mutual effects between IMHB and cation- $\pi$ interactions, the complexes of MES $\bullet \bullet M(M=$ $\left.\mathrm{Li}^{+}, \mathrm{Na}^{+}, \mathrm{K}^{+}, \mathrm{Be}^{2+}, \mathrm{Mg}^{2+}, \mathrm{Ca}^{2+}\right)$ are considered as the benchmark systems. In addition, to achieve further insight, the parent molecule (MES) and the 3-aminobenzoic acid complexes (ABA••M) are elected as a set of reference points. Figure 1 illustrates the molecular structures of MES $\bullet \bullet M$ and ABA $\bullet \bullet M$ complexes. The values of the calculated binding energies with the BSSE correction $\left(\Delta \mathrm{E}_{\mathrm{BSSE}}\right)$ for all complexes at the wB97XD/6-311++G $(\mathrm{d}, \mathrm{p})$ level of theory are demonstrated in Table 1. As can be seen in this Table, the absolute values of $\Delta \mathrm{E}_{\mathrm{BSSE}}$ increase for both MES and ABA complexes as $\pi \cdot \bullet \cdot \mathrm{Be}^{2+}>\pi \bullet \bullet \mathrm{Mg}^{2+}>\pi \bullet \bullet \bullet \mathrm{Ca}^{2+}>\pi \bullet \bullet \mathrm{Li}^{+}>\pi \bullet \bullet \mathrm{Na}^{+}>\pi \bullet \bullet \mathrm{K}^{+}$. The 
computations also indicate that the increase in the binding energies of $\pi \cdot . \bullet \mathrm{M}$ systems is correlated with the increment in the charge-to-radius ratio of cations as $\mathrm{Be}^{2+}(6.452)>\mathrm{Mg}^{2+}(3.077)>\mathrm{Ca}^{2+}(2.020)>\mathrm{Li}^{+}(1.667)>$ $\mathrm{Na}^{+}(1.052)>\mathrm{K}^{+}(0.752)$. For the studied complexes, the linear correlation coefficient $\left(\mathrm{R}^{2}\right)$ for the $\Delta \mathrm{E}_{\mathrm{BSSE}}$ dependency on charge-to-radius ratio of cations amounts to 0.9744 .

As it is apparent from Table 1, the presence of IMHB diminishes the strength of cation- $\pi$ interactions (except for $\mathrm{Be}^{2+}$ complex). In other words, our findings show the lower $\triangle \mathrm{E}_{\mathrm{BSSE}}$ values for MES... $\mathrm{M}$ complexes in comparison with the corresponding values of the ABA $\cdots \mathrm{M}$ (ranging from $0.06-1.15 \mathrm{kcal} \mathrm{mol}^{-1}$ ). The maximum and minimum changes are related to the MES $\bullet \cdot \mathrm{Li}^{+}$and MES.$\cdot \mathrm{Ca}^{2+}$ complexes, respectively. This may be due to the electrostatic attraction effects between the metal ions and the lone pairs of nitrogen and oxygen atoms of the $\mathrm{NH}_{2}$ and $\mathrm{OH}$ functional groups connected to the benzene ring. In fact, the negative charges on these atoms can transfer a certain amount of electron density towards the metal ions. This leads to less attraction between the ions and the MES ring, which weakens the cation $-\pi$ interaction strength in these systems.

In this investigation, the approximate values of the IMHB energies are estimated by the Espinosa and Molins method [39]. Herein, the hydrogen bond interaction energy $\left(\mathrm{E}_{\mathrm{HB}}\right)$ may be correlated with the electronic potential energy at the bond critical point $\left(\mathrm{Vr}_{\mathrm{Cp}}\right)$ by the expression $\mathrm{E}_{\mathrm{HB}}=1 / 2 \mathrm{~V}\left(\mathrm{r}_{\mathrm{cp}}\right)$ [39-41]. As observed in Table 1, the mutual influences of the IMHB and cation- $\pi$ interactions decrease the IMHB strength. It can be seen that the decline in the IMHB energies of MES complexes with respect to its monomer is in the range of $0.19-1.22, \mathrm{kcal}$ $\mathrm{mol}^{-1}$. Therefore, the IMHB strength for the studied complexes reduces in the following order: $\pi \cdot \bullet \mathrm{K}^{+}>\pi \cdot \bullet \cdot \mathrm{Na}^{+}>$ $\pi \cdot \bullet \cdot \mathrm{Li}^{+}>\pi \cdot \bullet \cdot \mathrm{Ca}^{2+}>\pi \cdot \bullet \cdot \mathrm{Mg}^{2+}>\pi \cdot \bullet \cdot \mathrm{Be}^{2+}$, which has a reverse relationship with the ratio of charge-to-radius of cations. It is worth mentioning that the $\mathrm{HB}$ energies nicely correlate with the binding energies $\left(\triangle \mathrm{E}_{\mathrm{BSSE}}\right)$. The correlation coefficient $\left(R^{2}\right)$ is equal to 0.9311 .

Table 1 The BSSE-corrected binding and IMHB energies $\left(\Delta \mathrm{E}_{\mathrm{BSSE}}\right.$ and $\mathrm{E}_{\mathrm{HB}}$, in $\left.\mathrm{kcal} \mathrm{mol}^{-1}\right)$, the the geometrical (bond lengths (d), in $\AA$ and bond angles $(\theta)$, in ${ }^{\circ}$ ) and spectroscopic descriptors $\left(v\right.$, in $\left.\mathrm{cm}^{-1}\right)$ of complexes calculated at the $w B 97 X D / 6-311++G(d, p)$ level of theory. 


\begin{tabular}{|c|c|c|c|c|c|c|c|c|}
\hline & $\Delta \mathrm{E}_{\mathrm{BSSE}}$ & $d_{\pi \cdots M}$ & $v_{\pi \cdots M}$ & $\mathrm{E}_{\mathrm{HB}}$ & $d_{\mathrm{O}-\mathrm{H}}$ & $d_{H \cdots O}$ & $\theta_{\mathrm{OHO}}$ & $v_{\mathrm{O}-\mathrm{H}}$ \\
\hline$A B A \bullet \bullet \bullet \mathrm{Li}^{+}$ & -37.81 & 1.951 & 339.9 & - & - & - & - & - \\
\hline ABA $\cdots \mathrm{Na}^{+}$ & -25.58 & 2.499 & 194.1 & - & - & - & - & - \\
\hline ABA $\bullet \mathrm{K}^{+}$ & -19.53 & 2.894 & 137.8 & - & - & - & - & - \\
\hline $\mathrm{ABA} \cdot \bullet \cdot \mathrm{Be}^{2+}$ & -235.00 & 1.316 & 642.6 & - & - & - & - & - \\
\hline ABA $\bullet \bullet \mathrm{Mg}^{2+}$ & -121.46 & 1.955 & 370.6 & - & - & - & - & - \\
\hline ABA $\cdots \mathrm{Ca}^{2+}$ & -87.57 & 2.348 & 296.8 & - & - & - & - & - \\
\hline MES & - & - & - & -11.29 & 0.974 & 1.786 & 144.0 & 3620.0 \\
\hline MES $\bullet \bullet \bullet \mathrm{Li}^{+}$ & -36.66 & 1.955 & 328.9 & -10.93 & 0.976 & 1.795 & 141.6 & 3581.9 \\
\hline MES $\bullet . \bullet \mathrm{Na}^{+}$ & -24.75 & 2.500 & 191.2 & -11.05 & 0.976 & 1.792 & 142.0 & 3591.5 \\
\hline MES $\bullet \bullet \mathrm{K}^{+}$ & -18.89 & 2.890 & 115.7 & -11.10 & 0.976 & 1.791 & 142.2 & 3591.9 \\
\hline MES $\bullet \bullet B^{2+}$ & -235.90 & 1.331 & 663.0 & -10.07 & 0.984 & 1.816 & 137.6 & 3481.7 \\
\hline MES $\bullet . M^{2+}$ & -120.89 & 1.951 & 366.9 & -10.34 & 0.981 & 1.810 & 138.6 & 3522.9 \\
\hline MES... $\mathrm{Ca}^{2+}$ & -87.51 & 2.331 & 295.7 & -10.78 & 0.980 & 1.798 & 139.3 & 3529.7 \\
\hline
\end{tabular}

Table 1 also presents the obtained geometrical parameters for cations $\left(\mathrm{Li}^{+}, \mathrm{Na}^{+}, \mathrm{K}^{+}, \mathrm{Be}^{2+}, \mathrm{Mg}^{2+}\right.$ and $\left.\mathrm{Ca}^{2+}\right)$ with the different $\pi$-systems of MES and ABA. For the studied complexes, the dependence between $\triangle \mathrm{E}_{\mathrm{BSSE}}$ and $\mathrm{d}_{\pi \cdots \cdot \cdot \mathrm{M}}$ (the distance between the ion and the center of aromatic ring) values can be considered. It is well known that strengthening of the cation $-\pi$ interaction leads to shortening of the $d_{\pi \ldots . M}$ distance. Our findings reveal that the coexistence of the IMHB and cation- $\pi$ interactions increases the distance between the cation and ring centre in the MES $\cdot . \cdot \mathrm{Li}^{+}$and MES $\cdot . \mathrm{Na}^{+}$complexes when are compared to the correspouding values of the ABA complexes. This indicates the presence of IMHB decreases the strength of the cation- $\pi$ interaction in these complexes. For instance, the cation $-\pi$ distance $\left(\mathrm{d}_{\pi \ldots . . \mathrm{M}}\right)$ of MES $\cdots \cdot \mathrm{Li}^{+}$complex becomes longer at about $0.004 \AA$ with respect to the ABA..• $\mathrm{Li}^{+}$one. However, a meaningful relationship cannot be observed between the calculated $d_{i o n} \cdots \pi$ values and the obtained binding energies in the other complexes (see Table 1). For the investigated complexes, the $d_{\pi \cdots \cdot M}$ values are arranged in the order of $\pi \cdot \bullet \cdot \mathrm{Ca}^{2+}>\pi \cdot \bullet \mathrm{Mg}^{2+}>\pi \bullet \bullet \bullet \mathrm{Be}^{2+}$ for alkaline-earth complexes and $\pi \bullet \bullet \mathrm{K}^{+}>\pi \bullet \bullet \mathrm{Na}^{+}>\pi \bullet \bullet \mathrm{Li}^{+}$for alkali ones. This trend depends on cation type. As observed, the highest the charge/radius ratio of cations corresponds to the lowest $d_{\pi \ldots M M}$ value upon complexation and vice versa.

The geometrical parameters of the quasi-ring created by the formation of $\mathrm{HB}$ are also analyzed to obtain a detailed insight into the nature of IMHB in the presence of cation- $\pi$ interactions. For this purpose, we have considered the determining factors of HB strength, i.e., the HB distances and its corresponding angles [42]. As it is obvious from Figure 1, the predicted IMHB in the formation of complexes is $0-\mathrm{H} \cdots \mathrm{O}$. It is well known that the 
formation of strong $\mathrm{HBs}$ is accompanied with (i) the elongation of the O凶H bond length $\left(\mathrm{d}_{\mathrm{O}-\mathrm{H}}\right)$ as proton donor (ii) the shortening of the $\mathrm{H} \cdots \mathrm{O}$ distance $\left(\mathrm{d}_{\mathrm{H}} \ldots \mathrm{O}\right)$ as proton acceptor and (iii) the increment of the $\mathrm{O}-\mathrm{H} \cdots \mathrm{O}$ angle $\left(\theta_{\mathrm{OHO}}\right)[43]$. The HB geometrical parameters of complexes such as bond length and bond angles are presented in Table 1.

The calculated results show that in comparison with the geometrical parameters obtained for the MES complexes, the parent molecule (MES) has the lowest $d_{H \ldots O}$ and $d_{O-H}$ values and the highest $\theta_{\mathrm{OHO}}$ value. The increase of the $\mathrm{d}_{\mathrm{O}-\mathrm{H}}$ and $\mathrm{d}_{\mathrm{H} \cdots \mathrm{O}}$ during the formation of complexes, as already mentioned, may be due to the electrostatic attraction effects between metal ions and the oxygen atom of $\mathrm{OH}$ functional group connected to the benzene ring. This causes that the oxygen atom transfers a certain amount of electron density towards the metal ions. Thus, it leads to increasing the bond lengths in these complexes. According to these results, it can be seen that the coupling of cation $-\pi$ and IMHB interactions decreases the IMHB strength. However, the trend of the $d_{H \cdots O}$ values for the studied complexes is as $\pi \bullet \bullet \cdot \mathrm{Be}^{2+}>\pi \bullet \bullet \mathrm{Mg}^{2+}>\pi \bullet \bullet \mathrm{Ca}^{2+}>\pi \bullet \bullet \mathrm{Li}^{+}>\pi \bullet \bullet \mathrm{Na}^{+}>\pi \bullet \bullet \bullet \mathrm{K}^{+}$, which is in agreement with the charge-to-radius ratio of the cations. As shown in Figure 2, there are good correlations between the values of $\mathrm{d}_{\mathrm{H} \ldots \mathrm{O}}$ and $\mathrm{d}_{\mathrm{O}-\mathrm{H}}$ versus the $\mathrm{E}_{\mathrm{HB}}$; the correlation coefficients $\left(\mathrm{R}^{2}\right)$ are equal to 0.9989 and 0.9365 , respectively. These data also correlate very well with the binding energies (see Fig. 3 ).

Shift of stretching frequencies is another quantity that can be useful to evaluate the strength of NCls. It is prominent that the stronger the binding energy is accompanied with the larger the frequencies shifting. Table 1 shows the stretching frequencies of the cation $-\pi$ contact $\left(v_{\pi \bullet . M}\right)$ for the analyzed complexes. As can be seen in this Table, with the exception of $\pi \bullet \bullet B^{2+}$ complex, the coexistence of IMHB and cation $-\pi$ interactions reduces the values of $v_{\pi \bullet \bullet M}$. This means that the strength of cation $-\pi$ interactions in the MES complexes is lower than the ABA ones. For instance, the value of the $v_{\pi \bullet \bullet M}$ for MES $\bullet \bullet \mathrm{Li}^{+}$complex is lower than the analogous value of ABA $\bullet \bullet \mathrm{Li}^{+}$(about $11 \mathrm{~cm}^{-1}$ ). On the other hand, the amplified $\mathrm{v}_{\pi \bullet \bullet M}$ value for MES $\bullet \bullet \mathrm{Be}^{2+}$ complex is $20 \mathrm{~cm}^{-1}$, which confirms the cation $-\pi$ interaction for this complex is stronger than the $\mathrm{ABA} \bullet \bullet \mathrm{Be}^{2+}$ one.

One of the most important vibrational modes of an $\mathrm{O}-\mathrm{H} \bullet \bullet \bullet \mathrm{O}$ unit, which considerably affects the nature of $\mathrm{IMHB}$, is the $\mathrm{O}-\mathrm{H}$ stretching frequency $\left(\mathrm{v}_{\mathrm{O}-\mathrm{H}}\right)$. The obtained $\mathrm{v}_{\mathrm{O}-\mathrm{H}}$ values for the studied complexes are represented in Table 1. As can be seen, the simultaneous presence of cation $\nabla \pi$ and IMHB interactions decreases the $\mathrm{v}_{\mathrm{O}-\mathrm{H}}$ values of the MES complexes in comparison with the parent molecule, which leads to reduction of the HB strength in these complexes. It is evident from the conventional definition of HB that formation of $X-H \cdots Y$ bond is accompanied by a weakening and elongation of the covalent $\mathrm{X}-\mathrm{H}$ bond with concomitant decrease of $\mathrm{X}-\mathrm{H}$ stretching frequency [44]. Based on our theoretical results, the $\mathrm{v}_{\mathrm{O}-\mathrm{H}}$ values for the MES complexes show red shifted by ca. $\pi \bullet \bullet B^{2+}(138)>\pi \bullet \bullet \mathrm{Mg}^{2+}(97)>\pi \bullet \bullet \mathrm{Ca}^{2+}(90)>\pi \bullet \bullet \mathrm{Li}^{+}(38)>\pi \bullet \bullet \mathrm{Na}^{+}(29)>\pi \bullet \bullet \mathrm{K}^{+}\left(28 \mathrm{~cm}^{-1}\right)$ with respect to MES monomer, which is in good accordance with the ratio of charge-to-radius of cations. In fact, the lengthening of the proton donating bond as an effect of HB formation is accompanied with the red shifted of its corresponding mode. As can be observed, the greatest/smallest shifts belong to $\mathrm{Be}^{2+} / \mathrm{K}^{+}$complexes, respectively. These results have good linear relationships with the $\Delta E_{B S S E}\left(R^{2}=0.9291\right), E_{H B}\left(R^{2}=0.9017\right)$ and $\mathrm{d}_{\mathrm{O}-\mathrm{H}}\left(\mathrm{R}^{2}=0.9912\right)$.

Shift of stretching frequencies is another quantity that can be useful to evaluate the strength of NCls. It is prominent that the stronger the binding energy is accompanied with the larger the frequencies shifting. Table 1 
shows the stretching frequencies of the cation $-\pi$ contact $\left(v_{\pi \bullet \bullet M}\right)$ for the analyzed complexes. As can be seen in this Table, with the exception of $\pi \cdot \bullet B^{2+}$ complex, the coexistence of IMHB and cation- $\pi$ interactions reduces the values of $v_{\pi \bullet \bullet M}$. This means that the strength of cation $-\pi$ interactions in the MES complexes is lower than the $\mathrm{ABA}$ ones. For instance, the value of the $\mathrm{v}_{\pi \bullet \bullet \mathrm{M}}$ for MES $\bullet \bullet \mathrm{Li}^{+}$complex is lower than the analogous value of ABA $\bullet \bullet \mathrm{Li}^{+}$(about $11 \mathrm{~cm}^{-1}$ ). On the other hand, the amplified $\mathrm{v}_{\pi \bullet \bullet M}$ value for MES $\bullet \bullet B e^{2+}$ complex is $20 \mathrm{~cm}^{-1}$, which confirms the cation $-\pi$ interaction for this complex is stronger than the $A B A \bullet \bullet \bullet \mathrm{Be}^{2+}$ one.

In the quantum theory of atoms in molecules (QTAIM) [34,45], the electron density $(\rho)$ and its Laplacian ( $\left.s^{2} \rho\right)$ along with the $\rho$ gradient paths, reveal the structure of the system through its stationary points. The total electron energy density $(H)$ and its components $(G$, kinetic electron energy density, and V, potential electron energy density) at the bond critical points (BCPs) are the other characteristics to investigation of these systems. In the present study, the existence of cation- $\pi$ interactions is confirmed by the BCPs formed between the different cations and the MES ring. The molecular graph of complexes shows one or two bond critical points in its structures, depending on the type of cation and $\pi$-system (see Fig. 4).

The topological properties of electron density calculated by AIM analysis are reported in Table 2. As it is obvious from this Table, in the presence of IMHB, the $\rho(r)_{\pi \bullet \bullet M}$ values for the MES complexes become lower in comparison with the ABA $\bullet$ M ones. For instance, the $\rho(r)_{\pi \bullet M M}$ value obtained in the MES $\bullet \bullet \mathrm{Li}^{+}$complex, is about $0.184 \times 10^{-2}$ a.u. lower than that of found in the $\mathrm{ABA} \cdot \bullet \mathrm{Li}^{+}$. In most cases, a direct relationship can be observed between the $\rho(r)_{\pi \bullet . M}$ values and the ratio of charge-to-radius of cations. In addition, there is an excellent linear relationship between the $\rho(r)_{\pi \cdots M}$ values and the binding energies with a correlation coefficient at about $\left(R^{2} \approx 0.9881\right)$.

The other topological properties can be also considered for investigating the complexes. The calculated electron density parameters indicate that these interactions have the low $\rho(r)_{\pi \cdots M}, s^{2} \rho(r)_{\pi \cdots M}>0$ and $H(r)_{\pi \cdots M}>0$ that these values display characteristics of the closed-shell interactions (except for $\pi \bullet \bullet B e^{2+}$ complexes). Nevertheless in $\mathrm{Be}^{2+}$ complexes, the corresponding $\mathrm{H}(\mathrm{r})$ value is negative, which means these interactions are at least partly covalent. Furthermore, the -G/V ratio can be applied as a criterion of the NCls character [46,47]: for $\mathrm{G} / \mathrm{V} \geq 1$ the interaction is electrostatic, while for $0.5<-\mathrm{G} / \mathrm{V}<1$, it is partly covalent. With the exception of Be $\mathrm{B}^{2+}$ complexes, the obtained $-G / V_{\pi \bullet .}$ values demonstrate that the cation- $\pi$ interactions in the systems under consideration have the electrostatic nature (see Table 2). These results also confirm that the $\mathrm{Be}^{2+}$ complexes are at least partly covalent.

Table 2 The selected topological properties of electron density (a.u. $\times 10^{2}$ except $-\mathrm{G} / \mathrm{V}$ ) obtained by AIM analysis. 


\begin{tabular}{|c|c|c|c|c|c|c|c|c|c|c|}
\hline & & $\pi \cdots M$ & & & & & & $\mathrm{HB}$ & & \\
\hline & $\rho(r)$ & $s^{2} \rho(r)$ & $H(r)$ & $V(r)$ & $-G / V$ & $\rho(r)$ & $s^{2} \rho(r)$ & $H(r)$ & $V(r)$ & $-G / V$ \\
\hline ABA $\bullet \bullet \mathrm{Li}^{+}$ & 1.642 & 8.964 & 0.442 & -1.356 & 1.326 & - & - & - & - & - \\
\hline $\mathrm{ABA} \bullet \bullet \mathrm{Na}^{+}$ & 1.013 & 4.961 & 0.277 & -0.686 & 1.404 & - & - & - & - & - \\
\hline ABA $\bullet \bullet K^{+}$ & 0.976 & 3.806 & 0.189 & -0.573 & 1.330 & - & - & - & - & - \\
\hline $\mathrm{ABA} \bullet \bullet \mathrm{Be}^{2+}$ & 6.386 & 22.549 & -1.050 & -7.738 & 0.864 & - & - & - & - & - \\
\hline ABA $\cdots \mathrm{Mg}^{2+}$ & 3.019 & 14.615 & 0.378 & -2.899 & 1.130 & - & - & - & - & - \\
\hline$A B A \cdot \cdot \cdot \mathrm{Ca}^{2+}$ & 2.831 & 9.563 & 0.042 & -2.307 & 1.018 & - & - & - & - & - \\
\hline MES & - & - & - & - & - & 3.849 & 12.912 & -0.184 & -3.595 & 0.949 \\
\hline MES $\bullet \bullet \bullet \mathrm{Li}^{+}$ & 1.458 & 7.590 & 0.383 & -1.132 & 1.338 & 3.766 & 12.600 & -0.165 & -3.479 & 0.953 \\
\hline MES $\bullet \bullet \mathrm{Na}^{+}$ & 0.957 & 4.506 & 0.252 & -0.623 & 1.404 & 3.794 & 12.690 & -0.172 & -3.518 & 0.951 \\
\hline MES $\bullet \bullet K^{+}$ & 0.970 & 3.744 & 0.185 & -0.565 & 1.328 & 3.807 & 12.735 & -0.176 & -3.536 & 0.950 \\
\hline $\mathrm{MES} \cdot \bullet \cdot \mathrm{Be}^{2+}$ & 6.143 & 21.543 & -0.950 & -7.288 & 0.870 & 3.566 & 11.848 & -0.122 & -3.205 & 0.962 \\
\hline MES $\bullet \bullet M^{2+}$ & 2.873 & 12.527 & 0.270 & -2.592 & 1.104 & 3.627 & 12.109 & -0.132 & -3.291 & 0.960 \\
\hline MES...C $\mathrm{Ca}^{2+}$ & 2.439 & 8.659 & 0.133 & -1.900 & 1.070 & 3.736 & 12.406 & -0.165 & -3.432 & 0.952 \\
\hline
\end{tabular}

Table 2 also displays the computed electron density properties of HB critical points for MES and its derivatives. The existence of $\mathrm{HB}$ in the considered complexes is confirmed by the presence of corresponding bond path in the electron density (see Figure 4a). Theoretical results show that the coupling of the cation $-\pi$ and IMHB interactions diminishes the $\rho(r)_{\mathrm{H} \ldots \mathrm{O}}$ at the $\mathrm{HB}$ critical points. For the analyzed complexes, the $\rho(r)_{\mathrm{H} \ldots .}$ values decrease in the following order $\pi \cdot \bullet \cdot \mathrm{K}^{+}>\pi \cdot \bullet \cdot \mathrm{Na}^{+}>\pi \cdot \bullet \bullet \mathrm{Li}^{+}>\pi \cdot \bullet \bullet \mathrm{Ca}^{2+}>\pi \cdot \bullet \bullet \mathrm{Mg}^{2+}>\pi \cdot \bullet \cdot \mathrm{Be}^{2+}$. A reverse relationship is present between the $\rho(r)_{\mathrm{H} \ldots . .0}$ values and the charge-to-radius ratio of cations. Furthermore, as observed in Figure 5, the obtained $\rho(r)_{H} \ldots . .0$ values with the AIM methodology show good relationships with the binding energies and the $\mathrm{d}_{\mathrm{O}-\mathrm{H}}$ values.

Rozas et al. [48] categorized HBs in proportion to their strength as the normal or weak (conventional) HBs with $s^{2} \rho(r)>0$ and $H(r)>0$, the moderate (medium) HBs with $s^{2} \rho(r)>0$ and $H(r)<0$ and also, the strong HBs or proton shared (ion-pair) with $s^{2} \rho(r)<0$ and $H(r)<0$. The topological analysis of the electron density at the WB97XD/6-311++G(d,p) level indicates that the studied systems are described by the $s^{2} \rho(r)_{H} \ldots 0>0$ and $H(r)_{H} \ldots .0$ $<0$ values. This means that they may be classified as medium HBs. Moreover, the obtained $-G / V_{H} \ldots .0$ values display that the HBs in the analyzed systems are partly covalent (see Table 2).

A better understanding of the molecular interactions in the complexes is provided by natural bond orbital (NBO) analysis. There is a significant $\pi_{\mathrm{C}=\mathrm{C}} \rightarrow \mathrm{LP}^{*}{ }_{\mathrm{M}}$ charge transfer between the cations and the MES ring in the studied 
complexes. The results of NBO analysis including second order perturbation interaction energy $\left(E^{(2)}\right)$, charge transfer $\left(\Delta \mathrm{q}_{\mathrm{CT}}\right)$ and occupancy of NBOs at the wB97XD/6-311++G $(\mathrm{d}, \mathrm{p})$ level of theory are given in Table 3. As observed in this Table, the coexistence of the IMHB and cation- $\pi$ interactions reduces the strength of cation $-\pi$ interactions (except for $\mathrm{Be}^{2+}$ complex). For example, in the MES $\bullet \bullet \mathrm{Mg}^{2+}$ complex, the $\mathrm{E}^{(2)}$ value amounts to $15.76 \mathrm{kcal} \mathrm{mol}^{-1}$, i.e., about $3.06 \mathrm{kcal} \mathrm{mol}^{-1}$ lower than that obtained for the $\mathrm{ABA} \cdot . \cdot \mathrm{Mg}^{2+}$ complex. Our findings show that the $\mathrm{E}^{(2)}$ value of complexes increases in the following order $\pi \cdot \bullet \cdot \mathrm{Be}^{2+}>\pi \cdot \bullet \cdot \mathrm{Mg}^{2+}>\pi \cdot \bullet \bullet \mathrm{Ca}^{2+}>\pi \cdot \bullet \bullet \mathrm{Li}^{+}$ $>\pi \bullet \bullet \mathrm{Na}^{+}>\pi \bullet \bullet \mathrm{K}^{+}$, which is in agreement with the ratio of charge-to-radius of cations.

Table 3 displays the values of charge transfer $\left(\Delta \mathrm{q}_{(\mathrm{CT} 1)}\right)$ obtained for the explored complexes. From the difference of charges between free cation and complexed cation, the charge transfer amount between the aromatic ring and cation is calculated. Our data exhibit that the simultaneous presence of cation $\pi$ and IMHB interactions diminishes the charge transfer $\left(\Delta \mathrm{q}_{(\mathrm{CT} 1)}\right)$ values for the MES complexes in comparison with $A B A$ ones. These outcomes are directly proportional to charge transfer energyies $\left(E^{(2)}\right)$.

In the NBO analysis of $\mathrm{HB}$ systems, the $\mathrm{LP}_{(\mathrm{O})} \rightarrow \sigma^{*}{ }_{(\mathrm{O}-\mathrm{H})}$ interaction shows the most important charge transfer between the $\mathrm{LP}_{(\mathrm{O})}$ of the proton acceptor and the $\sigma^{*}(\mathrm{O}-\mathrm{H})$ of the proton donor. The results of NBO analysis achieved for $\mathrm{O}-\mathrm{H} \cdots \mathrm{O}$ unit are listed in Table 3. As can be seen in this Table, the presence of cation- $\pi$ interaction reduces the IMHB strength. For instance, the decreased $\mathrm{E}^{(2)}$ value for MES... $\mathrm{Mg}^{2+}$ complex is about $1.92 \mathrm{kcal}$ $\mathrm{mol}^{-1}$ with respect to the parent molecule. The comparison of the charge transfer energies in the MES complexes shows that the maximum and minimum value of $\mathrm{E}^{(2)}$ is related to the $\mathrm{K}^{+}$and $\mathrm{Be}^{2+}$ complexes, respectively. As shown in Table 3, a reverse correlation exists between the ratio of charge-to-radius of cations and the $\mathrm{LP}_{(\mathrm{O})} \rightarrow \sigma^{*}(\mathrm{O}-\mathrm{H})$ interaction energy. Besides, there are the excellent linear correlations between the values of $E^{(2)}$ corresponding to $H B$ versus the $\rho_{H \ldots O}\left(R^{2}=0.9916\right), d_{O-H}\left(R^{2}=0.9439\right)$ and $\Delta E_{B S S E}\left(R^{2}=0.928\right)$.

Table 3 The values of $\mathrm{E}^{(2)}$ correspond to $\pi_{(\mathrm{C}=\mathrm{C})} \rightarrow \mathrm{LP}^{*}{ }_{(\mathrm{M})}$ and $\mathrm{LP}_{(\mathrm{O})} \rightarrow \sigma^{*}{ }_{(\mathrm{O}-\mathrm{H})}$ interactions (in kcalmol${ }^{-1}$ ), occupation numbers of donor $\left(\mathrm{ON}_{\mathrm{D}}\right)$ and acceptor $\left(\mathrm{ON}_{\mathrm{A}}\right)$ orbitals and the charge transfers $\left(\Delta \mathrm{q}_{(\mathrm{CT})}\right.$ in e) in the studied complexes. 


\begin{tabular}{|c|c|c|c|c|c|c|c|c|c|}
\hline & & $\pi \cdots M$ inte & action & & & & HB inter & & \\
\hline & & $\pi_{(\mathrm{C}=\mathrm{C})} \rightarrow$ & ${ }^{* *}(M)$ & & & & $\mathrm{LP}_{(0)} \rightarrow$ & $\mathrm{D}-\mathrm{H})$ & \\
\hline & $E^{(2)}$ & $\mathrm{ON}_{\pi(\mathrm{C}=\mathrm{C})}$ & $\begin{array}{l}\mathrm{ON}_{\mathrm{LP} *} \\
(\mathrm{M})\end{array}$ & $\Delta \mathrm{q}_{(\mathrm{CT} 1)}$ & $E^{(2)}$ & $\mathrm{ON}_{\mathrm{LP}(0)}$ & $\begin{array}{l}\mathrm{ON}_{\sigma^{\star}(\mathrm{O}-} \\
\mathrm{H})\end{array}$ & $q_{(0)}$ & $\Delta \mathrm{q}_{(\text {(ст2) }}$ \\
\hline $\mathrm{ABA} \bullet \bullet \mathrm{Li}^{+}$ & 3.49 & 1.699 & 0.025 & 0.410 & - & - & - & - & - \\
\hline $\mathrm{ABA} \bullet \bullet \mathrm{Na}^{+}$ & 1.39 & 1.665 & 0.012 & 0.162 & - & - & - & - & - \\
\hline ABA $\cdots \mathrm{K}^{+}$ & 0.60 & 1.664 & 0.008 & 0.024 & - & - & - & - & - \\
\hline $\mathrm{ABA} \cdots \mathrm{Be}^{2+}$ & 64.42 & 1.613 & 0.227 & 1.560 & - & - & - & - & - \\
\hline ABA $\cdots \mathrm{Mg}^{2+}$ & 18.82 & 1.692 & 0.108 & 1.093 & - & - & - & - & - \\
\hline $\mathrm{ABA} \cdot . \cdot \mathrm{Ca}^{2+}$ & 9.39 & 1.705 & 0.049 & 0.541 & - & - & - & - & - \\
\hline MES & - & - & - & - & 14.25 & 1.854 & 0.037 & -0.344 & - \\
\hline MES $\bullet \bullet \mathrm{Li}^{+}$ & 2.71 & 1.651 & 0.020 & 0.373 & 13.49 & 1.847 & 0.036 & -0.271 & -0.073 \\
\hline MES $\bullet \bullet \mathrm{Na}^{+}$ & 1.15 & 1.739 & 0.009 & 0.147 & 13.66 & 1.849 & 0.036 & -0.284 & -0.060 \\
\hline MES $\bullet \bullet K^{+}$ & 0.54 & 1.739 & 0.009 & 0.019 & 13.77 & 1.850 & 0.036 & -0.292 & -0.052 \\
\hline $\mathrm{MES} \cdot \bullet \cdot \mathrm{Be}^{2+}$ & 71.80 & 1.638 & 0.189 & 1.523 & 11.88 & 1.832 & 0.035 & -0.188 & -0.156 \\
\hline MES $\bullet \bullet M^{2+}$ & 15.76 & 1.602 & 0.112 & 1.062 & 12.33 & 1.838 & 0.035 & -0.215 & -0.129 \\
\hline MES $\bullet . \mathrm{Ca}^{2+}$ & 6.43 & 1.628 & 0.077 & 0.535 & 13.05 & 1.841 & 0.036 & -0.231 & -0.113 \\
\hline
\end{tabular}

The amounts of the charge transfer $\left(\Delta \mathrm{q}_{(\mathrm{CT} 2)}\right)$ related to the IMHB are also reported in Table 3 . As seen in this Table, the presence of cation- $\pi$ interaction decreases the negative charge value of the oxygen atoms of the MES complexes $\left(\mathrm{q}_{0}\right)$ in comparison with the parent molecule. The $\Delta \mathrm{q}_{(\mathrm{CT} 2)}$ value is determined as the difference between the atomic charge of the oxygen involved in $\mathrm{HB}$ of complexes and the charge of oxygen atom in its corresponding monomer with an equation as: $\Delta \mathrm{q}_{(\mathrm{CT} 2)}=\mathrm{q}_{\mathrm{o}}$ (complex) - $\mathrm{q}_{\mathrm{o}}$ (monomer). The obtained results show that the highest charge transfer $\left(\Delta \mathrm{q}_{(\mathrm{CT2})}\right)$ is observed for the $\mathrm{K}^{+}$complex and the lowest that is belonged to the $\mathrm{Be}^{2+}$ complex. Therefore, the charge transfer may be a significant characteristic in determining the strength of these interactions.

The frontier orbitals (HOMO and LUMO) of the chemical species are very important in defining its chemical stability and reactivity $[49,50]$. An instance from the plots of $\mathrm{HOMO}$ and LUMO for the $\mathrm{Li}^{+}$complexes is illustrated in Figure 6. The HOMO energy describes the ability of electron giving; LUMO characterizes the capability of electron accepting [51]. The HOMO-LUMO energy gap $\left(E_{g}\right)$, which is defined as the HOMO-LUMO energy separation of a molecule, is a simple indicator of kinetic stability [52]. The quantum molecular descriptors such as softness (S), chemical hardness ( $\eta$ ) [53], electronic chemical potential $(\mu)$ [54], global electrophilicity power $(\omega)[55]$ and electronegativity $(X)$ [56] for the studied complexes are presented in Table 4. 
These descriptors are able to measure the whole response of an electronic system to a chemical perturbation [57]. The obtained relationships are as follows:

$$
\begin{aligned}
& \eta=\frac{\left(E_{\text {LUMO }}-E_{\text {HOMO }}\right)}{2} \\
& \mu=\frac{\left(E_{\text {LUMO }}+E_{\text {HOMO }}\right)}{2} \\
& S=\frac{1}{2 \eta}
\end{aligned}
$$

where $\mathrm{E}_{\mathrm{HOMO}}$ and $\mathrm{E}_{\mathrm{LUMO}}$ are the energies of the HOMO and LUMO orbitals, respectively. The equation of electrophilicity index can be also evaluated as follows:

$$
\omega=\frac{\mu^{2}}{2 \eta}
$$

From energy gap between HOMO and LUMO, one can find whether the molecule is hard or soft. The larger the $\mathrm{E}_{\mathrm{g}}$ is attributed to the harder the molecule. It is well known that a large gap indicates high stability and a small gap shows high chemical reactivity. The $\eta$ and $\mu$ are appropriate parameters for estimating the reactivity of molecules. In other words, the compounds with the values of lower $\eta$ and higher $|\mu|$ will be more reactive because necessary electron transmissions for performance of a chemical reaction can be done in them more suitably $[58,59]$. It is clear from Table 4 that the values of negative $\mu$ indicate that all complexes are stable. The $\chi$ is defined as the negative of $\mu$, as: $\chi=-\mu$. Hence, the complexes having the highest $\chi$ value are the best electron acceptors. The $\omega$ is also a useful tool in predicting the reactivity of the molecule. It has been found that there is a correlation between the $\omega$ of various chemical compounds and the rate of reaction in the biochemical systems [60].

Table 4 Values of the HOMO and LUMO energies ( $\left.E_{\text {HOMO }}, E_{L U M O}\right)$, energy gap $\left(E_{g}\right)$, chemical hardness $(\eta)$, softness $(S)$, electronic chemical potential $(\mu)$, electronegativity $(X)$ and electrophilicity index $(\omega)$ interms of eV. 


\begin{tabular}{|c|c|c|c|c|c|c|c|c|}
\hline & $\mathrm{E}_{\mathrm{HOMO}}$ & $\mathrm{E}_{\text {LUMO }}$ & $E_{g}$ & $\eta$ & $S$ & $\mu$ & $x$ & $\omega$ \\
\hline ABA $\bullet \bullet \mathrm{Li}^{+}$ & -12.623 & -4.173 & 8.449 & 4.225 & 0.118 & -8.398 & 8.398 & 8.347 \\
\hline ABA $\bullet \bullet \mathrm{Na}^{+}$ & -12.122 & -3.746 & 8.376 & 4.188 & 0.119 & -7.934 & 7.934 & 7.516 \\
\hline ABA $\bullet \mathrm{K}^{+}$ & -11.852 & -3.484 & 8.368 & 4.184 & 0.120 & -7.668 & 7.668 & 7.026 \\
\hline $\mathrm{ABA} \bullet \cdot \mathrm{Be}^{2+}$ & -18.519 & -9.901 & 8.618 & 4.309 & 0.116 & -14.210 & 14.210 & 23.430 \\
\hline $\mathrm{ABA} \cdot \bullet \cdot \mathrm{Mg}^{2+}$ & -17.403 & -10.140 & 7.261 & 3.631 & 0.138 & -13.772 & 13.772 & 26.122 \\
\hline $\mathrm{ABA} \cdot . \cdot \mathrm{Ca}^{2+}$ & -16.755 & -8.853 & 7.902 & 3.951 & 0.127 & -12.804 & 12.804 & 20.745 \\
\hline MES & -7.592 & 0.082 & 7.674 & 3.837 & 0.130 & -3.755 & 3.755 & 1.838 \\
\hline MES $\bullet \bullet \bullet \mathrm{Li}^{+}$ & -12.071 & -4.344 & 7.726 & 3.863 & 0.129 & -8.208 & 8.208 & 8.719 \\
\hline MES $\bullet . \bullet \mathrm{Na}^{+}$ & -11.618 & -3.910 & 7.708 & 3.854 & 0.130 & -7.764 & 7.764 & 7.821 \\
\hline MES $\bullet \bullet K^{+}$ & -11.377 & -3.658 & 7.719 & 3.859 & 0.130 & -7.517 & 7.517 & 7.322 \\
\hline $\mathrm{MES} \bullet \bullet \cdot \mathrm{Be}^{2+}$ & -17.980 & -9.930 & 8.049 & 4.025 & 0.124 & -13.955 & 13.955 & 24.194 \\
\hline MES $\bullet \bullet M^{2+}$ & -16.586 & -10.110 & 6.478 & 3.239 & 0.154 & -13.347 & 13.347 & 27.497 \\
\hline MES $\bullet . \cdot \mathrm{Ca}^{2+}$ & -16.109 & -8.952 & 7.157 & 3.578 & 0.140 & -12.530 & 12.530 & 21.939 \\
\hline
\end{tabular}

As it is apparent from Table 4, the presence of IMHB decreases the $E_{g}, \eta$ and $\chi$ descriptors for MES complexes in comparison with the ABA ones. In contrast, the indices of $S, \mu$ and $\omega$ show the greater values for these complexes. Our findings also show that with the exception of $\mathrm{Mg}^{2+}$ and $\mathrm{Ca}^{2+}$ complexes, the coexistence of cation $\nabla \pi$ and IMHB interactions increases the values of $E_{g}, \eta, \chi$ and $\omega$ and decreases the descriptors of $S$ and $\mu$ for MES complexes with respect to the parent molecule. As can be seen, both cation- $\pi$ and HB interactions have reverse trend for these indices (except for $\omega$ ), indicating that the effect of HB on the cation- $\pi$ interaction is different from the effect of the cation- $\pi$ interaction on HB.

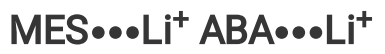

In addition to the above-mentioned electronic descriptors, another index that gives the visual representation of the chemically active sites and comparative reactivity of atoms is the molecular electrostatic potential (MPE). The MEP 3D plots of the $\mathrm{Li}^{+}$complexes are drawn in Figure 7. As observed, while regions having the negative potential are over the oxygen electronegative atoms (red and yellow colors), the regions having the positive potential are over $\mathrm{Li}^{+}$cations and plane of the MES ring (blue color).

\section{Conclusions}

In the present research, the effects of interplay between cation- $\pi$ and IMHB interactions in the MES complexes with $\mathrm{Li}^{+}, \mathrm{Na}^{+}, \mathrm{K}^{+}, \mathrm{Be}^{2+}, \mathrm{Mg}^{2+}$ and $\mathrm{Ca}^{2+}$ cations are evaluated. In order to understand the mutual effects of these 
interactions, the geometrical parameters, binding energies, topological properties and charge transfer analysis are examined on the studied complexes and their results are compared to the corresponding values of $A B A$ complexes and the parent molecule of MES as a set of reference points. According to the calculated descriptors, it can be concluded that the coupling simultaneously weakens both of the interactions (with the exception of $\mathrm{Be}^{2+}$ complex). Our findings also demonstrate that with the increment in the ratio of charge-to-radius of cations, the strength of cation $-\pi$ interactions increases, while for IMHB interactions, the reverse process is observed. The results of molecular orbital analysis also show that both cation- $\pi$ and $H B$ interactions have reverse trend for the quantum molecular descriptors (except for $\omega$ ), indicating that the effect of HB on the cation- $\pi$ interaction is different from the effect of the cation- $\pi$ interaction on HB. Several correlations are found between the energetic, geometrical and topological parameters. Hence, the interplay between these NCls that are ubiquitous in biological systems may be important in many areas of the supramolecular chemistry.

\section{Declarations}

\section{Acknowledgements}

The support of this work by Vali-e-Asr University of Rafsanjan is acknowledged.

\section{Conflict of interest}

The authors declare that they have no conflict of interest.

\section{References}

1. lacucci, M., de Silva, Sh., Ghosh, S.: Mesalazine in inflammatory bowel disease: A trendy topic once again?. Can. J. Gastroenterol. 24, 127-133 (2010)

2. Rubin, G., Hungin, A.P.S., Chinn, D., Dwarakanath, A.D., Green, L., Bates, J., Long-term aminosalicylate therapy is under-used in patients with ulcerative colitis.: A cross-sectional survey. Aliment. Pharmacol. Ther. $16,1889-1893$ (2002)

3. Nielsen, O.H., Bukhave, K., Elmgreen, J., Ahnfelt-Ronne, I.: Inhibition of 5-lipoxygenase pathway of arachidonic acid metabolism in human neutrophils by sulfasalazine and 5-aminosalicylic acid. Dig. Dis. Sci. 32, 577-582 (1987)

4. Mahida, Y.R., Lamming, C.E., Gallagher, A., Hawthorne, A.B., Hawkey, C.J.: 5-Aminosalicylic acid is a potent inhibitor of interleukin-1 beta production in organ culture of colonic biopsy specimens from patients with inflammatory bowel disease. Gut. 32, 50-54 (1991)

5. Kaiser, G.C., Yan, F., Polk, D.B.: Mesalamine blocks tumor necrosis factor growth inhibition and nuclear factor kappa B activation in mouse colonocytes. Gastroenterol. 116, 602-609 (1999)

6. Meyer, E.A., Castellano, R.K., Diederich, F.: Interactions with aromatic rings in chemical and biological recognition. Angew. Chem. Int. Ed. 42, 1210-1250 (2003)

7. Perrin, C.L., Nielson, J.B.: "Strong" hydrogen bonds in chemistry and biology. Annu. Rev. Phys. Chem. 48, 511-544 (1997)

8. Desiraju, G.R.: Hydrogen Bridges in Crystal Engineering: Interactions without Borders. Acc. Chem. Res. 35, 565-573 (2002) 
9. Jeffrey, G.A., Saenger, W.: Hydrogen Bonding in Biology and Chemistry. Springer-Verlag, Berlin (1991)

10. Hobza, P., Havlas, Z.: Blue-Shifting Hydrogen Bonds. Chem. Rev. 100, 4253-4264 (2000)

11. Raissi, H., Yoosefian, M., Hajizadeh, A., Imampour, J.S., Karimi, M., Farzad, F.: Theoretical Description of Substituent Effects in 2,4-Pentanedione: AIM, NBO, and NMR Study. Bull. Chem. Soc. Jpn. 85, 87-92 (2012)

12. Wysokinski, R., Biennko, D.C., Michalska, D., Huyskens, T.Z.: Theoretical study of the interaction between cytosine and hydrogen peroxide. Chem. Phys. 315, 17-26 (2005)

13. Ma, J.C., Dougherty, D.A.: The Cation- $\pi$ Interaction. Chem. Rev. 97, 1303-1324 (1997)

14. An, Y., Wheeler, S.E.: Cation- $\pi$ interactions. In Encyclopedia of Inorganic and Bioinorganic Chemistry, Wiley \& Sons (2011)

15. Dougherty, D.A.: The cation- $\pi$ interaction. Acc. Chem. Res. 46, 885-893 (2013)

16. Muller-Dethlefs, K., Hobza, P.: Noncovalent Interactions: A Challenge for Experiment and Theory. Chem. Rev. $100,143-168$ (2000)

17. Nicholas, J.B., Hay, P.B., Dixon, D.A.: Binding Enthalpies for Alkali Cation-Benzene Complexes Revisited. J. Phys. Chem. A 104, 11414-11419 (2000)

18. Feller, D.: A complete basis set estimate of cation- $\pi$ bond strengths: $\mathrm{Na}^{+}$(ethylene) and $\mathrm{Na}^{+}($benzene). Chem. Phys. Lett. 322, 543-548 (2000)

19. Pullman, A., Berthier, G., Savinelli, R.: Components of the interaction energy of benzene with $\mathrm{Na}^{+}$and methylammonium cations. J. Mol. Struct. (Theochem) 537, 163-172 (2001)

20. Hunter, C.A., Sanders, J.K.M.: The nature of $\pi-\pi$ interactions. J. Am. Chem. Soc. 112, 5525-5534 (1990)

21. Estarellas, C., Escudero, D., Frontera, A., Quiñonero, D.: P.M. Deyá, Theoretical ab initio study of the interplay between hydrogen bonding, cation $-\pi$ and $\pi-\pi$ interactions. Theor. Chem. Acc. 122, 325-332 (2009)

22. Rezvani Rad, O., Nowroozi, A.: interplay between the IMHBs and cation- $\pi$ interactions in various complexes of salicylaldehyde, thiosalicylaldehyde and selenosalicylaldehyde with $\mathrm{Li}^{+}, \mathrm{Na}^{+}, \mathrm{K}^{+}, \mathrm{Mg}^{2+}$ and $\mathrm{Ca}^{2+}$ cations. Mol. Phys. 115, 784-794 (2017)

23. Nowroozi, A., Rezvani Rad, 0.: A comparative study of cooperative effects between the intramolecular hydrogen bond and cation $\cdots \pi$ interaction in various complexes of ortho-aminobenzaldehyde with its thio and seleno analogous. Theor. Chem. Acc. 136, 23 (2017)

24. Frisch, M.J., Trucks, G.W., Schlegel, H.B., Scuseria, G.E., Robb, M.A., Cheeseman, J.R., Scalmani, G., Barone, V., Mennucci, B., Petersson, G.A., Nakatsuji, H., Caricato, M., Li, X., Hratchian, H.P., Izmaylov, A.F., Bloino, J., Zheng, G., Sonnenberg, J.L., Hada, M., Ehara, M., Toyota, K., Fukuda, R., Hasegawa, J., Ishida, M., Nakajima, T., Honda, Y., Kitao, O., Nakai, H., Vreven, T., Montgomery Jr., J.A., Peralta, J.E., Ogliaro, F., Bearpark, M.J., Heyd, J., Brothers, E.N., Kudin, K.N., Staroverov, V.N., Kobayashi, R., Normand, J., Raghavachari, K., Rendell, A.P., Burant, J.C., Iyengar, S.S., Tomasi, J., Cossi, M., Rega, N., Millam, N.J., Klene, M., Knox, J.E., Cross, J.B., Bakken, V., Adamo, C., Jaramillo, J., Gomperts, R., Stratmann, R.E., Yazyev, O., Austin, A.J., Cammi, R., Pomelli, C., Ochterski, J.W., Martin, R.L., Morokuma, K., Zakrzewski, V.G., Voth, G.A., Salvador, P., Dannenberg, J.J., Dapprich, S., Daniels, A.D., Farkas, Ö., Foresman, J.B., Ortiz, J.V., Cioslowski, J., Fox, D.J.: Gaussian 09. Gaussian, Inc., Wallingford, CT, USA (2009)

25. Cohen, A.J., Sanchez, P.M., Yang, W.: Insights into Current Limitations of Density Functional Theory. Science $321,792-794$ (2008) 
26. Frisch, M.J., Pople, J.A., Binkley, J.S.: Self-consistent molecular orbital methods 25. Supplementary functions for Gaussian basis sets. J. Chem. Phys. 80, 3265-3269 (1984)

27. likura, H., Tsuneda, T., Yanai, T., Hirao, K.: A long-range correction scheme for generalized-gradientapproximation exchange functionals. J. Chem. Phys. 115, 3540 (2001)

28. Savin, A., Flad, H.J.: Density functionals for the Yukawa electron-electron interaction. Int. J. Quantum. Chem. 56, 327-332 (1995)

29. Chai, J.D., Head-Gordon, M.: Systematic optimization of long-range corrected hybrid density functionals. J. Chem. Phys. 128, 084106 (2008)

30. Chai, J.D., Head-Gordon, M.: Long-range corrected hybrid density functionals with damped atom-atom dispersion corrections. Phys. Chem. Chem. Phys. 10, 6615-6620 (2008)

31. Hobza P., Zahradnik R.: Intermolecular Complexes. Elsevier, Amsterdam (1988)

32. van Duijneveldt, F.B., van Duijneveldt-van de Rijdt, J.G.C.M., van Lenthe, J.H.: State of the Art in Counterpoise Theory. Chem. Rev. 94, 1873-1885 (1994)

33. Boys, S.F., Bernardi, F.: The calculation of small molecular interactions by the differences of separate total energies. Some procedures with reduced errors. Mol. Phys. 19, 553-556 (1970)

34. Bader, R.F.W.: Atoms in molecules: a quantum theory. Oxford University Press, New York (1990)

35. BieglerKönig, F., Schönbohm, J.: Update of the AIM2000-program for atoms in molecules. J. Comput. Chem. 23, 1489-1494 (2002)

36. Foster, J.P., Weinhold, F.: Natural hybrid orbitals. J. Am. Chem. Soc. 102, 7211-7218 (1980)

37. (a) Carpenter, J.E., Weinhold, F.: Analysis of the geometry of the hydroxymethyl radical by the "different hybrids for different spins" natural bond orbital procedure”. J. Mol. Struct. (Theochem) 169, 41-62 (1988)

(b) Reed, A.E., Weinstock, R.B., Weinhold, F.: Natural population analysis. J. Chem. Phys. 83, 735 (1985)

38. Glendening, E.D., Reed, A.E., Carpenter, J.E., Weinhold, F.: NBO. Version 3.1., Gaussian, Inc., CT, Pittsburgh (2009)

39. Espinosa, E., Molins, E.: Retrieving interaction potentials from the topology of the electron density distribution: the case of hydrogen bonds. J. Chem. Phys. 113, 5686-5694 (2000)

40. Espionsa, E., Souhassou, M., Lachekar, H., Lecomte, C.: Topological analysis of the electron density in hydrogen bonds. Acta. Crystallogr. B 55, 563-572 (1999)

41. Abramov, Y.A.: On the possibility of kinetic energy density evaluation from the experimental electron-density distribution. Acta. Crystallogr. A 53, 264-272 (1997)

42. Grabowski, S.J., Sokalski, W.A., Dyguda, E., Leszczyński, J.: Quantitative classification of covalent and noncovalent H-bonds. J. Phys. Chem. B 110, 6444-6446 (2006)

43. Dziembowska, T.: Intramolecular Hydrogen Bonding. Akademia Rolnicza, Szczecink (1990)

44. Steiner, T.: The hydrogen bond in the solid state. Angew. Chem. Int. Ed. 41, 48-76 (2002)

45. Bader, R.F.W.: Atoms in Molecules. Acc. Chem. Res. 18, 9-15 (1985)

46. Parra, R.D., Ohlssen, J.: Cooperativity in Intramolecular Bifurcated Hydrogen Bonds: An Ab Initio Study. J. Phys. Chem. A 112, 3492-3498 (2008)

47. Ziółkowski, M., Grabowski, S.J., Leszczynski, J.: Cooperativity in Hydrogen-Bonded Interactions: Ab Initio and "Atoms in Molecules" Analyses. J. Phys. Chem. A 110, 6514-6521 (2006)

Page $15 / 21$ 
48. Rozas, I., Alkorta, I., Elguero, J.: Behavior of ylides containing N, O and C atoms as hydrogen bond acceptors. J. Am. Chem. Soc. 122, 11154-11161 (2000)

49. Fukui, K., Yonezaw, T., Shingu, H.: A molecular orbital theory of reactivity in aromatic hydrocarbons. J. Chem. Phys. 20, 722-725 (1952)

50. Mendoza-Huizar, L.H., Rios-Reyes, C.H.: Chemical reactivity of atrazine employing the Fukui function. J. Mex. Chem. Soc. 55, 142-147 (2011)

51. Fukui, K.: Role of Frontier Orbitals in Chemical Reactions. Science 218, 747-754 (1982)

52. Kosar, B., Albayrak, C.: Spectroscopic investigations and quantum chemical computational study of (E)-4methoxy-2-[(p-tolylimino)methyl]phenol. Spectrochim. Acta. A 78, 160-167 (2011)

53. Pearson, R.G.: Chemical Hardness - Applications from Molecules to Solids. VCH-Wiley, Weinheim (1997)

54. Chattaraj, P. K., Poddar, A.: Molecular Reactivity in the Ground and Excited Electronic States through DensityDependent Local and Global Reactivity Parameters. J. Phys. Chem. A 103, 8691-8699 (1999)

55. Parr, R.G., Szentpály, Lv., Liu, S.: Electrophilicity Index. J. Am. Chem. Soc. 121, 1922-1924 (1999)

56. Sen, K.D., Jorgensen, C.K.: Electronegativity, Structure and Bonding. Springer Verlag, New York (1987)

57. Morell, C., Labet, V., Grand, A., Chermette, H.: Minimum electrophilicity principle: an analysis based upon the variation of both chemical potential and absolute hardness. Phys. Chem. Chem. Phys. 11, 3417-3423 (2009)

58. Jalali Sarvestani, M.R., Ahmadi, R.: Investigating the Complexation of a recently synthesized phenothiazine with Different Metals by Density Functional Theory. Int. J. New. Chem. 4, 101-110 (2017)

59. Jalali Sarvestani, M. R., Majedi, S.: A DFT study on the interaction of alprazolam with fullerene (C20). J. Chem. Lett. 1, 32-38 (2020)

60. Kamel, M., Morsali, A., Raissi, H., Mohammadifard, K.: Theoretical insights into the intermolecular and mechanisms of covalent interaction of Flutamide drug with $\mathrm{COOH}$ and $\mathrm{COCl}$ functionalized carbon nanotubes: A DFT approach. Chem. Rev. Lett. 3, 23-37 (2020)

\section{Figures}

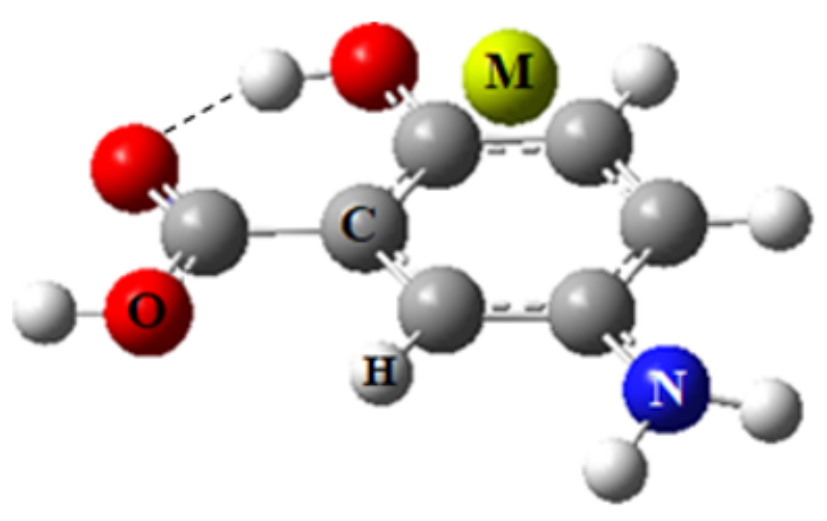

(a)

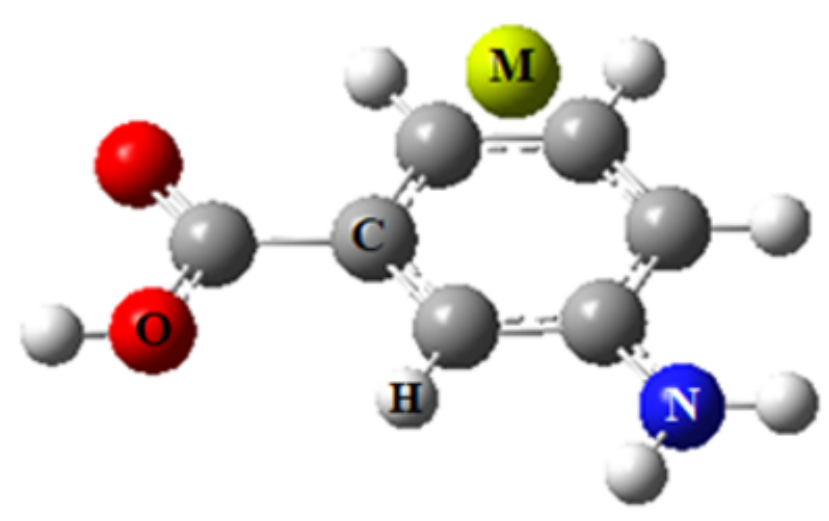

(b)

Figure 1 
Molecular structures of MES $\bullet \bullet M(a)$ and ABA $\bullet \bullet M(b)$ complexes $(\mathrm{M}=\mathrm{Li}+, \mathrm{Na}+, \mathrm{K}+, \mathrm{Be} 2+, \mathrm{Mg} 2+, \mathrm{Ca}+$ ).

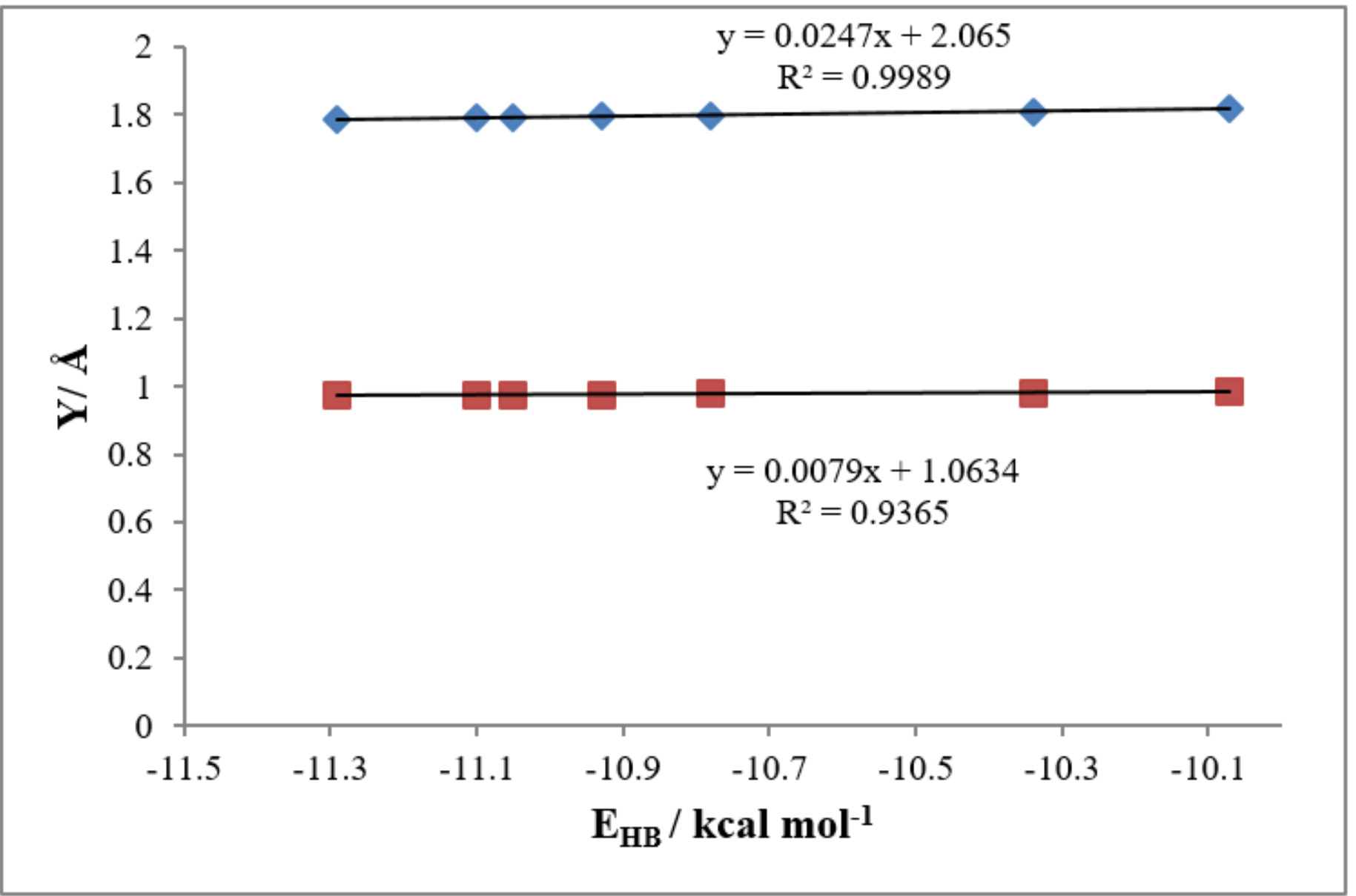

Figure 2

Correlation between the $\mathrm{dH} \ldots \mathrm{O}$ and $\mathrm{dO}-\mathrm{H}(\mathrm{Y})$ versus the EHB for MES $\bullet \bullet M$ complexes. $(\checkmark$ and $\square$ symbols correspond to $\mathrm{dH}$...O and $\mathrm{dO}-\mathrm{H}$, respectively). 


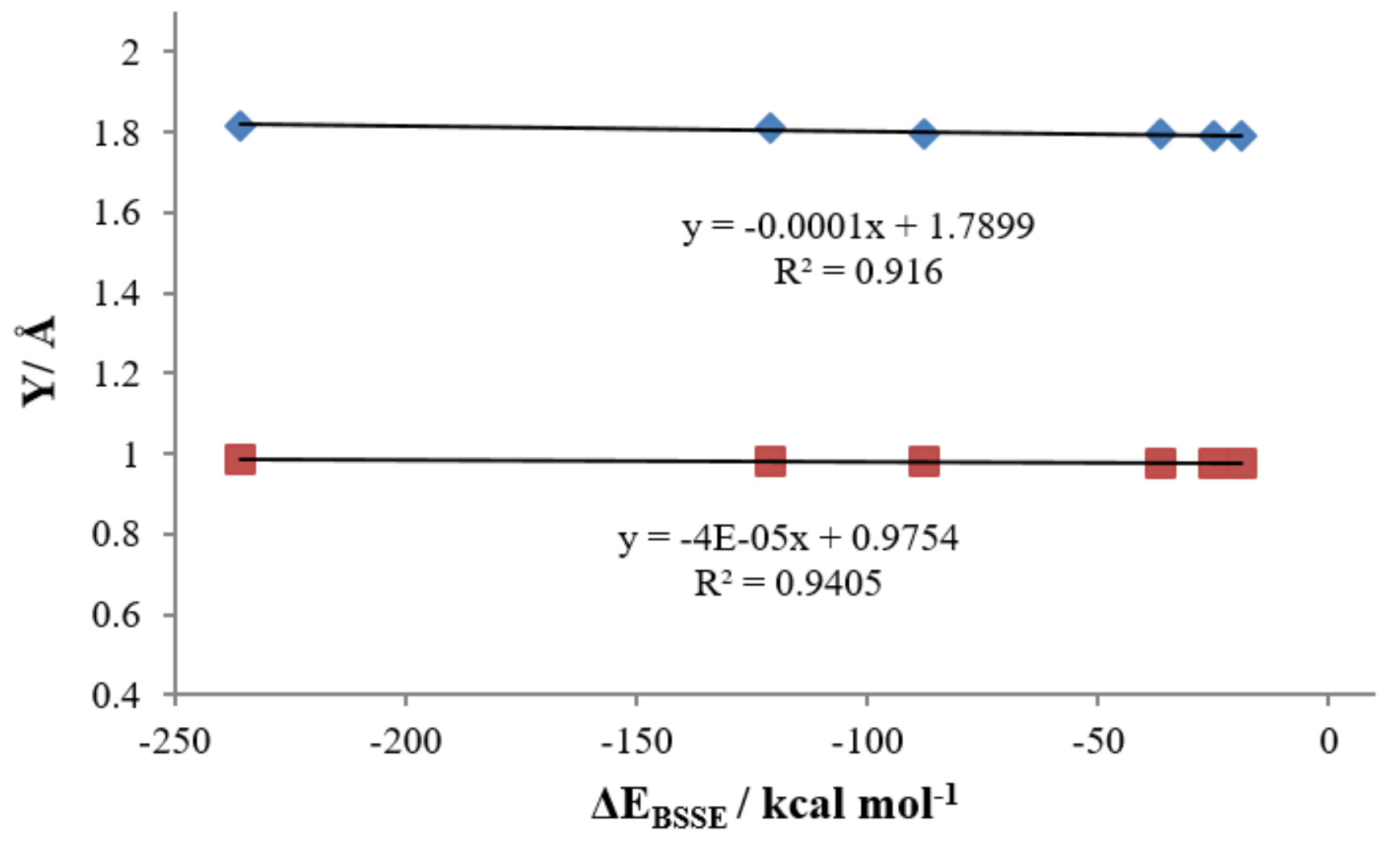

Figure 3

Correlation between the $\mathrm{dH}$...O and $\mathrm{dO}-\mathrm{H}(\mathrm{Y})$ versus the $\triangle$ EBSSE for MES $\bullet \bullet \mathrm{M}$ complexes. $(\checkmark$ and $\square$ symbols correspond to $\mathrm{dH}$...O and $\mathrm{dO}-\mathrm{H}$, respectively).

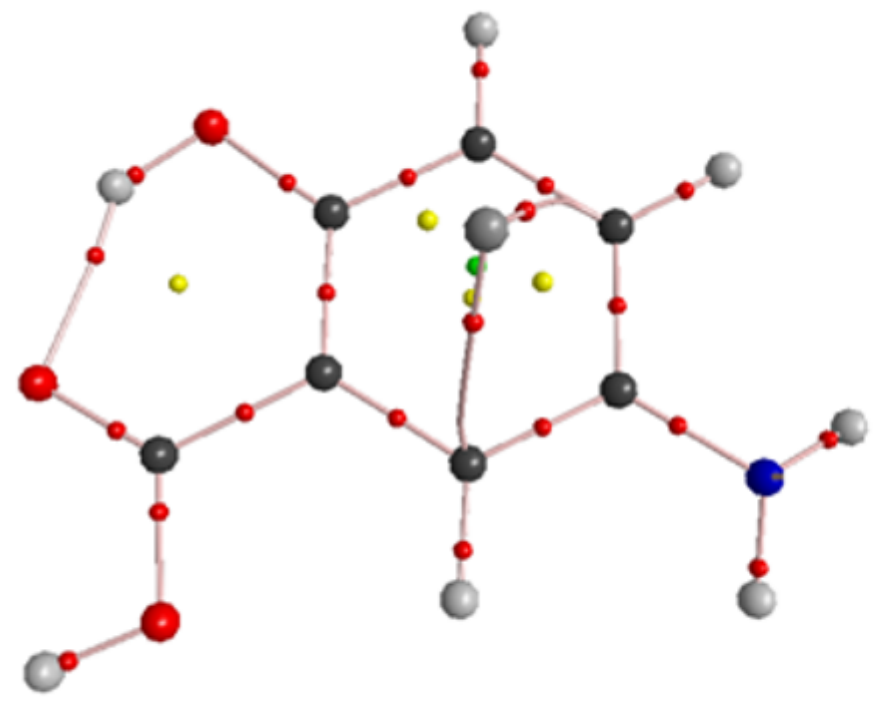

(a)

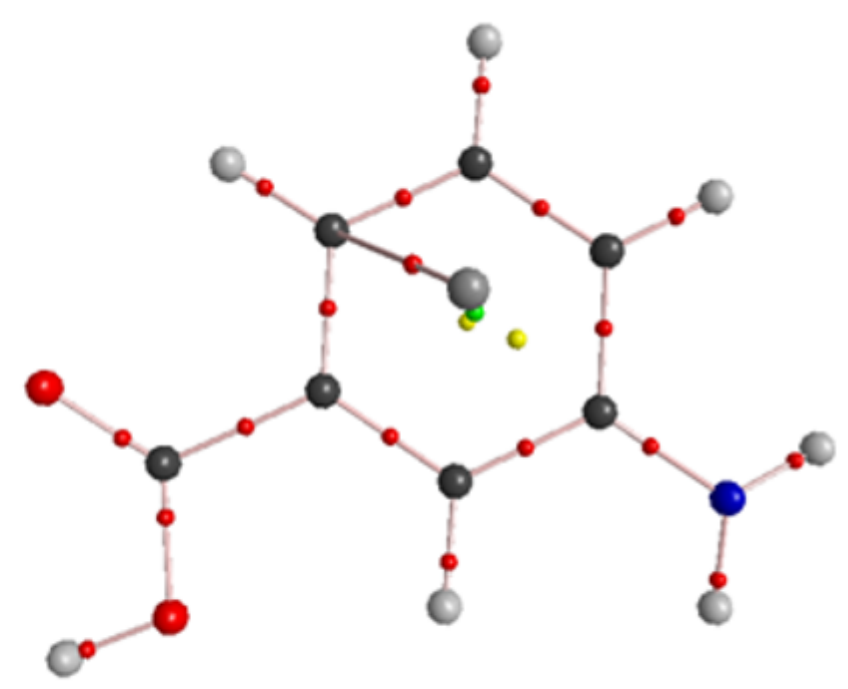

(b)

Figure 4 
Typical molecular graphs obtained from AIM analysis for MES $\bullet \bullet M(a)$ and ABA $\bullet \bullet M(b)$ complexes. The small red, yellow, green spheres, and lines correspond to bond critical points (BCPs), ring critical points (RCPs), cage critical point (CCP) and bond paths, respectively.

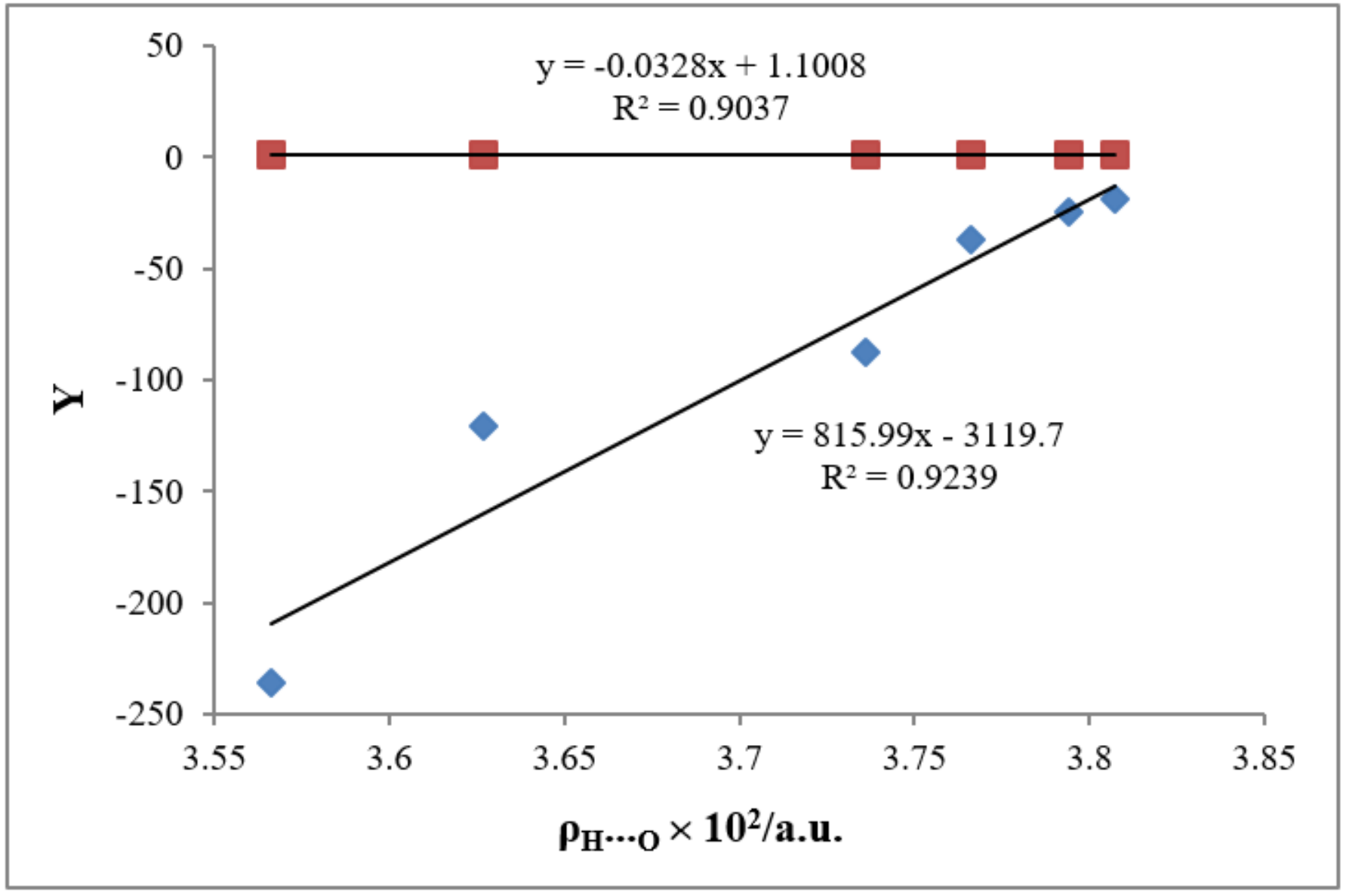

Figure 5

Correlation between the $\triangle \mathrm{EBSSE}$ and $\mathrm{dO}-\mathrm{H}(\mathrm{Y})$ versus the $\rho \mathrm{H} . . . \mathrm{O}$ for MES $\bullet \bullet M$ complexes. ( $\downarrow$ and $\square$ symbols correspond to $\triangle$ EBSSE (in kcal mol-1) and dO-H (in $\AA$ ), respectively). 


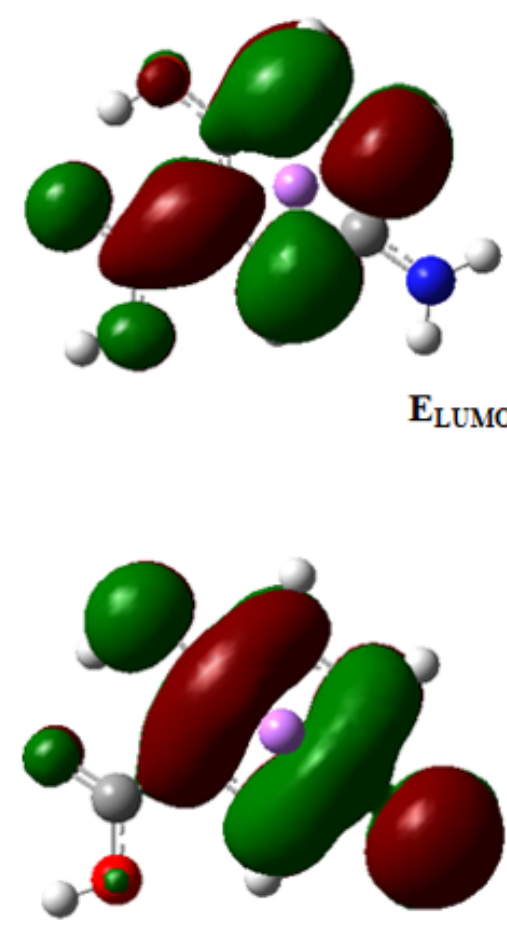

MES $\cdots \mathbf{L i}^{+}$

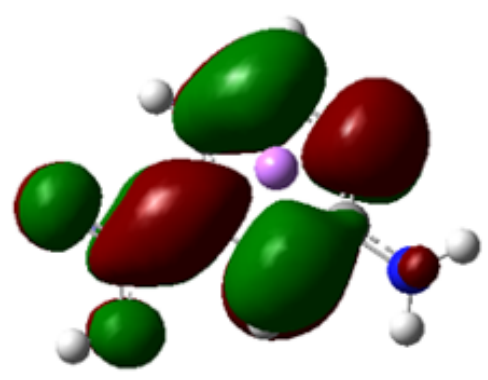

$\mathrm{E}_{\mathrm{LUMO}}=-4.17 \mathrm{eV}$

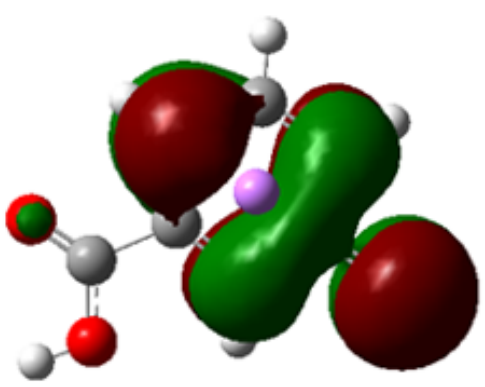

$E_{g}=8.45 \mathrm{eV}$

$\mathbf{A B A} \cdots \mathbf{L i}^{+}$

Figure 6

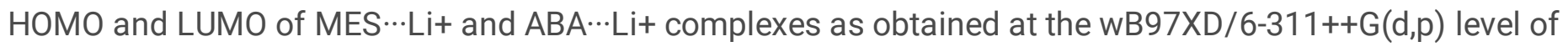
theory.

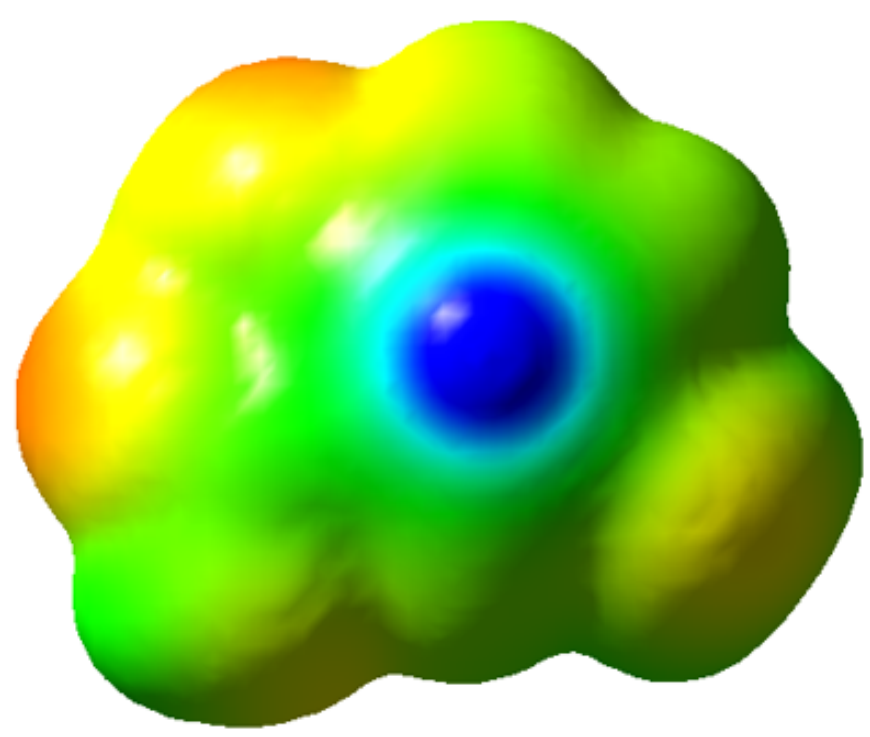

MES $\cdots \mathbf{L i}^{+}$

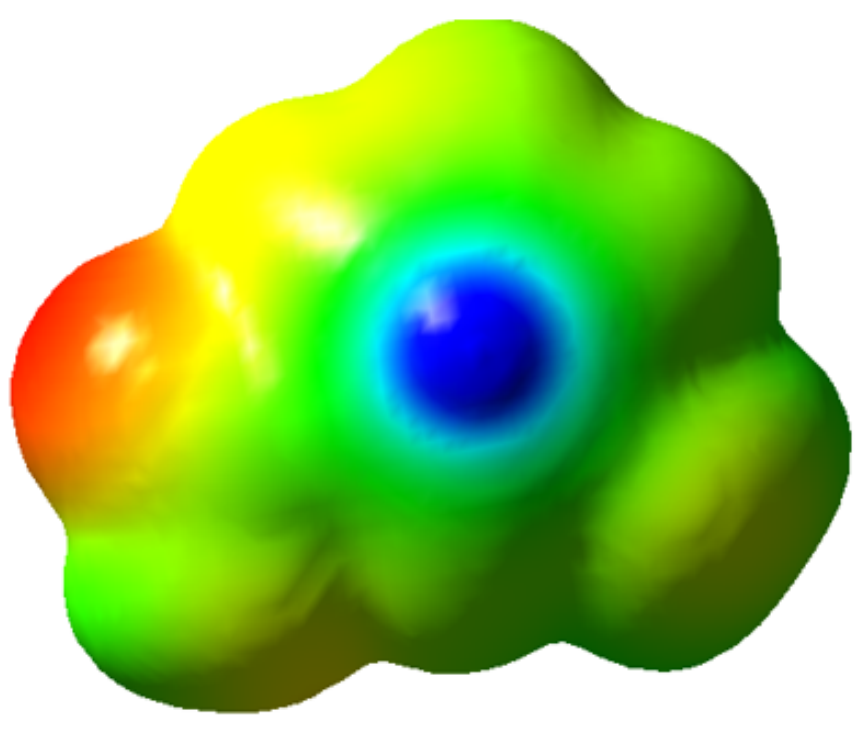

$\mathbf{A B A} \cdot \mathbf{L i}^{+}$

Figure 7 


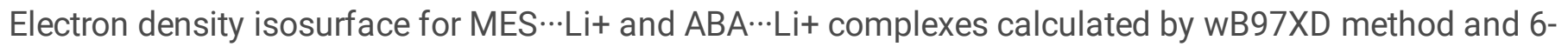
$311++G(d, p)$ basis set. 